Edith Cowan University

Research Online

Research outputs 2014 to 2021

$9-18-2020$

\title{
A pilot evaluation of simulation-based interprofessional education for occupational therapy, speech pathology and dietetic students: improvements in attitudes and confidence
}

\author{
Brennen Mills \\ Edith Cowan University \\ Sara Hansen \\ Edith Cowan University \\ Charn Nang \\ Edith Cowan University \\ Helen McDonald \\ Edith Cowan University \\ Philippa Lyons-Wall \\ Edith Cowan University
}

See next page for additional authors

Follow this and additional works at: https://ro.ecu.edu.au/ecuworkspost2013

Part of the Medicine and Health Sciences Commons

10.1080/13561820.2019.1659759

This is an Accepted Manuscript of an article published by Taylor \& Francis in Journal of Interprofessional Care on 18/09/2019, available online: http://www.tandfonline.com/10.1080/13561820.2019.1659759.

Mills, B., Hansen, S., Nang, C., McDonald, H., Lyons-Wall, P., Hunt, J., \& O’Sullivan, T. (2020). A pilot evaluation of simulation-based interprofessional education for occupational therapy, speech pathology and dietetic students: Improvements in attitudes and confidence. Journal of Interprofessional Care, 34(4), 472-480. https://doi.org/ 10.1080/13561820.2019.1659759

This Journal Article is posted at Research Online.

https://ro.ecu.edu.au/ecuworkspost2013/8801 


\section{Authors}

Brennen Mills, Sara Hansen, Charn Nang, Helen McDonald, Philippa Lyons-Wall, Jacqui Hunt, and Therese O'Sullivan 


\section{Title:}

A pilot evaluation of simulation-based interprofessional education for occupational therapy, speech pathology and dietetic students: Improvements in attitudes and confidence

\section{Authors:}

Dr Brennen Mills, Lecturer, School of Medical and Health Sciences, Edith Cowan University; Building 21, 270 Joondalup Drive, Edith Cowan University; Ph: +610863043947; Email: b.mills@ecu.edu.au (corresponding author)

Mrs Sara Hansen, Simulation Education Coordinator, School of Medical and Health Sciences, Edith Cowan University; 270 Joondalup Drive, Edith Cowan University; Ph: +610863042039; Email: s.hansen@ecu.edu.au

Dr Charn Nang, Lecturer, School of Medical and Health Sciences, Edith Cowan University; 270 Joondalup Drive, Edith Cowan University; Ph: +610863045168; Email: c.nang@ecu.edu.au

Ms Helen McDonald, Senior Lecturer, School of Medical and Health Sciences, Edith Cowan University; 270 Joondalup Drive, Edith Cowan University; Ph: +610863043413; Email: h.mcdonald@ecu.edu.au

Dr Philippa Lyons-Wall, Senior Lecturer, School of Medical and Health Sciences, Edith Cowan University; 270 Joondalup Drive, Edith Cowan University; Ph: +610863045676; Email: p.lyons-wall@ecu.edu.au

Ms Jacqui Hunt, Lecturer, School of Medical and Health Sciences, Edith Cowan University; 270 Joondalup Drive, Edith Cowan University; Ph: +610863043582; Email: j.hunt@ecu.edu.au

Dr Therese O'Sullivan, Associate Professor, School of Medical and Health Sciences, Edith Cowan University; 270 Joondalup Drive, Edith Cowan University; Ph: +610863043529; Email: t.osullivan@ecu.edu.au 


\section{ABSTRACT}

Many higher education institutions struggle to provide interprofessional practice opportunities for their pre-licensure students due to demanding workloads, difficulties with timetabling, and problems with sourcing suitable placements that provide appropriate practice opportunities. A series of complex unfolding video-based simulation scenarios involving a patient who had experienced a stroke was utilised as a case study for a three-hour interprofessional practice workshop. 69 occupational therapy (OT), speech pathology (SP) and dietetics (DT) students participated in a mixed-methods study comparing interprofessional attitudes before and after the workshop. Attitudes towards interprofessional practice improved pre- vs. post-workshop and overall. Students were highly satisfied with the workshops contribution toward learning, although OT and SP students were more satisfied than DT students. Focus groups confirmed students liked the format and structure of the workshop, suggested that students better understood the role of other professions and improved role clarification, increased their confidence to practice in interprofessional practice settings, but noted the experience could have been improved with the incorporation of nursing and smaller groups to better facilitate participation. There is widespread support for implementing interprofessional education (IPE) in the health sciences, yet widespread implementation is not yet a reality. This research suggests that a simulation-based, three-hour IPE workshop can have an immediate benefit on confidence and attitudes towards interprofessional practice for allied health students. 


\section{A pilot evaluation of simulation-based interprofessional education for occupational therapy, speech pathology and dietetic students: Improvements in attitudes and confidence}

\section{INTRODUCTION}

This study sought to trial and evaluate a novel simulation-based interprofessional education (IPE) activity for allied health students from occupational therapy (OT), speech pathology (SP) and dietetics (DT). Interprofessional Education (IPE), where 'students or members of two or more professions learn with, from and about each other to improve collaboration and the quality of care,' is vital to prepare healthcare students to effectively manage patients with increasingly complex healthcare needs (Centre for Advancement of Interprofessional Education, 2013). Limited IPE training opportunities leads to gaps between what is taught and what is expected upon graduation as an entry-level healthcare professional (Cox, Cuff, Brandt, Reeves \& Zierler, 2016). Despite health profession education accreditation standards recognising IPE as an important factor in preparing students for real world practice, opportunities to engage in an interprofessional manner are not always readily available in university education settings. Lack of resources, scheduling difficulties and shortages in clinical placement opportunities have all been identified as barriers to IPE in the academic setting (Gough, Hellaby, Jones \& MacKinnon, 2012).

Limited IPE training opportunities leads to gaps between what is taught and what is expected upon graduation as an entry-level healthcare professional (Cox et al. 2016). The use of simulation-based learning (SBL) environments has long been acknowledged as a way to safely acquire key skills and behaviours to help manage new and challenging healthcare situations (MacKinnon, 2011). Simulation aims to imitate reality whilst offering a clinical experience in 
a safe and secure environment (Cant \& Cooper, 2010). Integration of simulation into IPE delivery to replicate real-world settings and provide avenues for growth and innovation in training provision has been advocated for both students and members of healthcare teams (Robertson \& Bandali, 2008).

While SBL has been widely used in emergency medicine and crisis resource management training, provision of simulation-based education in the allied health professions is comparatively new (MacKinnon, 2011). Utilisation of SBL methodologies centred on IPE allows students to appropriately apply their knowledge to complex patient care issues in a realistic interprofessional setting. However, while IPE activities for medicine and nursing disciplines are relatively well investigated, there has been a call for better understanding of IPE in allied health curricula (Davidson, Smith, Dodd, Smith \& O'Loughlan, 2008). Further, the majority of IPE evaluation work surrounds practising health professionals, with questionable applicability to pre-licensure students, thus necessitating a need for further inquiry into prequalification, university-based IPE activities (Goldman, Zwarenstein, Bhattacharyya \& Reeves, 2009).

While many Australian universities have published interprofessional approaches to IPE with pre-licensure health professionals, few provide any evaluative data speaking to the generalisability of program utility (Thistlethwaite, 2007). The aim of the present study was to develop and trial a novel simulation-based IPE activity for allied health students from OT, SP and DT-three professions that have (to-date) been under-represented in the IPE literature, particularly in comparison to medicine and nursing. We hypothesised that following completion of our pilot IPE simulation-based group-work activity, our pre-licensure students would have improved understanding of, attitudes towards, and confidence with 
interprofessional practice (IPP). We also investigated differences in the perceived effectiveness of the experience between disciplines.

\section{BACKGROUND}

IPE activities are perceived as more relevant and successful when participants are organised in small stable groups, rather than large didactic-style lectures (Baker, Egan-Lee, Martinmianakis \& Reeves, 2011; Hayashi et al., 2012; Watt-Watson et al., 2004). Further, IPE interventions of less than 2.5 hours duration have been described by participants as being too brief (Cameron et al., 2009). Keeping these aspects in mind, the interprofessional team of study investigators developed a series of complex unfolding video-based simulation scenarios involving a patient who had experienced a stroke. Stroke was chosen as the appropriate clinical case for inclusion in the exercise given its clinical relevance to each of the three professions.

The clinical patient case and associated video-based scenario scripts were developed in a collaborative process with staff comprising of five separate disciplines: SP, OT, DT, nursing and simulation education. Following initial development, the case study and associated scripts were externally reviewed for content validity by a panel of qualified clinicians each with clinical experience working with adult neurological patients (four from SP, two from OT, two from DT, and two from nursing). Suggestions and changes ascertained from this process were incorporated into the final version of both the case study and scenario scripts. An external actor portrayed the standardised patient in the videos, with faculty staff members used to portray members of the interprofessional working group team. Editing of the videos was completed using Camtasia Studio (Techsmith, Michigan, USA). 
A clinical patient introduction was the first video scenario in the series and was utilised to visually reinforce the aspects of the written patient case study, which was provided to participants prior to the workshop. The second video scenario depicted an interprofessional team meeting where clinicians discussed the patient's clinical deterioration, including significant weight loss since arriving at the long-term care facility (LTCF), and formulated a plan for appropriate assessments and interventions going forward. Video scenario three depicted a clinical handover between team members following positioning and swallowing reassessments.

\section{METHODS}

\section{Workshop Delivery}

Participants completed the three-hour IPE workshop on one of two consecutive days in August 2017. IPE workshops were incorporated into mandatory participation activities for units in each of the three disciplines' course (OT, SP and DT). Students either attended a workshop during their normal unit hours or in place of another unit tutorial for that given week.

One week prior to the IPE workshop, all students received a short, written patient case study and a current patient medication chart for review. Upon arriving to the workshop, the students were placed into pre-determined randomised interprofessional teams. Teams comprised of 89 students each, ensuring at least one person from each discipline was included in each team. Staff members representing SP, OT and DT were present for the entirety of the workshop.

\section{Participants}

Participants included undergraduate OT and SP students and postgraduate DT students studying at Edith Cowan University (ECU) in Western Australia. 


\section{Occupational Therapy}

OT students were enrolled in their third-year of a four-year Bachelor of Science (Occupational Therapy) degree. Attendance at the IPL simulation workshop was made a mandatory component of the third-year neurological rehabilitation unit, implemented prior to them attending a 6-week practicum placement.

\section{Speech Pathology}

SP students were enrolled in their third-year of a four-year Bachelor of Speech Pathology degree. Attendance at the IPE simulation workshop was a component of the third-year professional issues unit. The majority of the students were concurrently undertaking a clinical practicum in the same semester.

\section{$\underline{\text { Dietetics }}$}

The Master of Nutrition and Dietetics is a two year degree integrating theoretical and practical components across clinical dietetics, food service, community and public health and research. In their final semester of four, students complete a set of practicum placements, including a clinical placement in a hospital setting. Students participating in this IPE simulation were in their third semester, prior to starting practicum placements.

\section{Measures}

A systematic review investigating the use of IPE in allied health found that studies utilising a mixed or quantitative-based methodology scored higher on reporting and methodological quality compared to those limited to qualitative designs alone (Olsen \& Bialocerkowski, 2014). 
However, we note that there are ongoing calls for more qualitative research in reviews of IPE (Thistlethwaite, 2012). We elected to utilise a mixed-methods study design.

\section{$\underline{\text { Readiness for Interprofessional Learning Scale (RIPLS) }}$}

The RIPLS questionnaire was given to study participants immediately before and after the IPE experience. The RIPLS is a 19-item, 5-point Likert scale reporting tool designed to assess the attitudes and perceptions of students and professionals to the importance of IPP (Parsell \& Bligh, 1999). While the original RIPLS factor structure proposed a three-factor solution, more recent psychometric work suggests a four-factor solution is more appropriate for university students (Williams, Brown \& Boyle, 2012). The four subscales include: (1) teamwork and collaboration, (2) negative professional identity, (3) positive professional identity, and (4) roles and responsibilities.

\section{$\underline{\text { Simulation Design Scale (Student Version) }}$}

The Simulation Design Scale (SDS) is a 20-item scale that assesses five subscales of perceptions of objectives, information, support, problem solving, feedback and fidelity in simulation. Participants are asked via a 5-point Likert scale to indicate the extent of their agreement with statements relating to the presence of simulation design features, and then to rate the importance of this particular feature to them personally (Jeffries \& Rizzoli, 2006). Items are separated into five subscales: (1) Objectives and information, (2) Support, (3) Problem Solving, (4) Feedback/Guided reflection, and (5) Fidelity (realism). Total scores and scores for each subscale are converted to percentages. This measure has been psychometrically validated amongst 2,200 nursing students in the USA, with authors suggesting the SDS met sufficient thresholds of validity and reliability to be used in education research (Franklin, Burns \& Lee, 2014). 


\section{Focus groups}

At the close of the IPE workshop, participants were invited to participate in a focus group discussing the IPE workshop. Participation in focus group discussions was voluntary. Focus groups took place the following week with each discussion being separated by study discipline. Discussion followed a semi-structured interview guide to ensure consistency across focus groups. The interview guide included a set list of topic points for the facilitator (who facilitated all four focus group discussions) to consider throughout their interviews, yet allowed flexibility to promote free-flowing discussion. Topic points included: (1) the structure and content of the workshop, (2) knowledge of other disciplines, (3) perceived changes in knowledge of their own discipline by other disciplines, (4) effects on confidence (particularly with respect to upcoming clinical practicums), (5) working in an interprofessional setting, and (6) suggested improvements to the workshop.

Two focus groups were held with OT students, one with SP students and one with DT students. Focus groups consisted of 8, 5, 11 and 6 students respectively and went for an average of 46 minutes. The four focus groups were facilitated by the same researcher. A pragmatic, actionresearch oriented, interpretive inquiry approach (Goldkuhl, 2012) was employed to explore the experiences of the students. Each focus group discussion was audio-recorded and transcribed verbatim with responses de-identified. Horizontalization of the data was performed whereby significant statements or quotes were coded into themes. After grouping statements into themes and sub-themes, a textual description was created describing participants' experiences. A composite description that presented the essence of the common experiences of participants was then formulated. Two coders (both experienced in undertaking qualitative data analysis 
and interpretation) independently reviewed focus group data to arrive at final consensus on code and theme identification.

\section{Ethical considerations}

This project was granted ethics approval from the Human Research Ethics Committee at Edith Cowan University (\#17636).

\section{RESULTS}

A total of 69 students participated in the simulation-based workshop. There were higher proportions of SP and OT students compared to DT students that participated in the event which was reflective of the student enrolments in the respective courses. A chi square analysis suggested there was no significant difference between the number of students from each discipline participating between workshops on Day 1 vs. Day $2(p=.576)$ (Table 1).

\section{[INSERT TABLE 1 HEREABOUTS]}

The average age of participants was 27.0 years $(\mathrm{SD}=8.175)$. There were no significant

differences between age of participants across disciplines $(p=0.965)$. The majority of participants were female $(\mathrm{n}=87 \%)$ with no significant differences between sex across disciplines $(p=0.586)$.

\section{Quantitative data}

$\underline{\text { Readiness for Interprofessional Learning Scale }}$

We received a $100 \%$ response rate both pre- and post-workshop, and there was no missing data. There were no significant differences between study professions for summed scores of the 
RIPLS scale (i.e. overall score) pre-workshop or post-workshop or for individual subscale factors 1-4 pre-workshop or post-workshop. However, when comparing the summed total of the RIPLS questionnaire pre- versus post-simulation workshop, a paired samples t-test suggested attitudes towards IPP improved (83.3\% pre-workshop vs. $90.2 \%$ post-workshop, $p<0.001, d=0.90)$. Separating out change in IPP attitudes into the four factors proposed by Williams, Brown and Boyle (2012), from pre-workshop to post-workshop there were statistically significant improvements in interprofessional attitudes across the factors of (1) teamwork and collaboration, (2) negative professional identity and (3) positive professional identity, but not for (4) roles and responsibilities (Table 2). The largest change pre- versus postworkshop was for the 'teamwork and collaboration' factor. These significant results remained after adjusting for Type I error via a Bonferroni correction.

\section{[INSERT TABLE 2 HEREABOUTS]}

Changes observed were similar between study disciplines, with no statistically significant differences being noted in change between disciplines pre- and post-workshop attitudes towards IPP overall $(p=0.461)$ or for factors one, two, three or four $(p=0.084,0.833,0.491$, 0.491 respectively).

\section{$\underline{\text { Simulation Design Scale }}$}

We received a $100 \%$ response rate to this scale, which was completed immediately after completion of the simulation workshop. There was no missing data. The mean overall score for satisfaction and importance for the entire sample was $84.7 \%(\mathrm{SD}=8.6 \%)$ and $84.2 \%$ $(\mathrm{SD}=10.9 \%)$ respectively. Percentage scores per SDS subscale for satisfaction and importance can be found in Figures 1 . 


\section{[INSERT FIGURE 1 HEREABOUTS]}

A series of paired samples t-tests suggested that students were more satisfied with the information surrounding 'Objectives and Information' compared to 'Support' $(p=0.001)$, 'Problem Solving' $(p<0.001)$ and 'Feedback' $(p<0.001)$. Students also suggested they were more satisfied with the level of 'Fidelity (realism)' compared to opportunities for 'problem solving' $(p<0.001)$. With respect to the importance students placed on different aspects, students reported that 'Objectives and Information', 'Feedback' and 'Fidelity (realism) were each more important than 'Problem Solving' ( $p<0.001, p<0.001, p<0.001$ respectively).

\section{Between-discipline comparisons}

A One-Way ANOVA suggested there was a statistically significant difference between

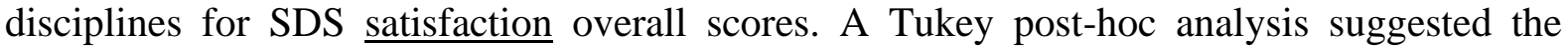
majority of this difference laid between OT and DT students (85.5 vs. 78.4, respectively, $p=0.034)$. The majority of these differences seemed attributable to the 'Feedback' $(p=0.028)$ and 'Fidelity (realism) $(p=0.037)$ subscales scores.

'Feedback' was suggested to be more important to both OT $(p=0.017)$ and SP $(p=0.029)$ students compared to DT students. 'Fidelity (realism)' in simulation was similarly suggested to be more important to both OT $(p=0.027)$ and SP $(p=0.045)$ students compared to DT students.

\section{Qualitative data}

$\underline{\text { Workshop content and structure }}$ 
Students typically agreed the case study was suitable for their discipline, as it included aspects relevant to OT, SP and DT. Some noted the workshop introduction by the lecturers that gave a background to each discipline was helpful in setting the scene. Most stated the complexity of the case was at an appropriate level, although some dietetic students (who were at postgraduate level) stated they would have liked a more complicated case.

"Our case was good. Relevant." "Aphasia, swallowing, that sort of stuff." - SP focus group

"I think I was maybe expecting it to be a little bit more complex. So in terms of learning as a person, me, it was more repetition; more consolidation of knowing that I just already have it covered". - OT2 focus group

The video component of the case study was the part of the workshop resources most commented on by the students. All comments were positive, with students noting the additional visual information helped them to better understand the patient at the centre of the case.

"The video was great because we can get a visual playback on positioning and things I think that was really valuable. Rather than just see a piece of paper, you can actually see her trying to eat a banana, so that was really valuable." - OT1 focus group

Students also appreciated seeing how multidisciplinary team meetings were conducted, and liked seeing their lecturers handle a situation in a modern video. 
“And it's always nice to see something...produced locally. Not an old American video from the 80 s for example." - OT2 focus group

"I'm actually seeing a real example of a patient and also actual team meetings and stuff so you can get some visual ideas." - OT1 focus group

Although the majority of students also commented the case was highly realistic, this view was not shared by some students.

"I can't see the scenario where you would actually sit down, have a meeting with OT's and speech - I just can't see that happening — everyone would be (too) busy" - DT focus group

The discussion sections of the workshop were also well received by all students. They noted the benefits of having small group discussions to share their thoughts, and then the large facilitated group discussion to hear varying views. Students also found the facilitation of the workshop helpful in consolidating treatment goals.

“The best part (was) where we had to think 'what were the common goals' and agree, and everyone from each discipline would come together to discuss. You could clearly see like as OTs, we were coming from this field and then the dietitian takes up this opinion, and then the speechies have noted something else." - OT1 focus group

There was general agreement around students liking how the groups were left to their own devices when working on the case, and not being too closely supervised by the staff, yet having 
ready access to advice and feedback upon request. Comments on the environment for the workshop were also positive.

"I didn't know if it was going to be nervous or quite pressuring or anything but I think the environment was really comfortable and it was so easy to talk, between both the lecturers and also the students." - OT1 focus group

Timing of the workshop was important to students. Some expressed a preference for the workshop to run earlier in the semester or during semester break, so it didn't cut into their study and assignment preparation as much. They liked that the time spent in the workshop was accounted for by not having a lecture/tutorial for a given week in one of their subject units, so that it was not extra workload on top of their normal week. There was a discussion in one focus group about whether some pre-reading or videos could be sent to students to watch beforehand, but the consensus was that it might not be done.

"What student is going to do that when they have got a workload as high as ours you know? - SP focus group

\section{Knowledge of other disciplines}

Students from all focus groups noted the improvement in their own knowledge of how health professionals from the other disciplines operated. They also noted seeing value in what they brought to a case, and saw ways they could work together. 
"I definitely learnt a lot from the speechies, so much about what they do and what she's talking about with positioning and swallowing. I can see how we would work closely together." - OT1 focus group

"I think what was most interesting for me, in a practical setting, is I also work in a nursing home as a therapy assistant. I couldn't help thinking 'Man, I really wish we had some speech pathologists and dietitians in.' Because, we have quite a few residents that have strokes and other neurological conditions and I thought, it could be so helpful". OT2 focus group

Some students reflected on the traditional silos that the different disciplines normally work in within the university setting. For most students, it was the first time they had discussed a case with someone from a different allied health field.

"I think also it's nice to see ... collaborating... see you working with other people and not just in my own bubble. I think that's how you feel most of the time. You've got your discipline bubble." - OT2 focus group

\section{Perceived knowledge of own discipline by others}

All students reported feeling that students from other disciplines didn't really understand the extent of their role in healthcare, and noted some misconceptions. There was a general feeling that their knowledge wasn't appreciated as much as it could be. For example, DT students reported being stereotyped in weight loss roles:

"A lot of people think that dietitians are people who keep others on a diet, to lose weight." 
"It's funny, because on the day there were lollies on the table and guys were having misconceptions. 'Oh you know we better not have lollies next time'. As though we [dietitians] don't eat lollies!"

Similarly, the SP students also felt they were perceived as only involved with speech, as opposed to their other roles in swallow assessment and communication.

"I think people put speechies in a box. They think we're a pretend degree."

OT students also reported a general unawareness of what they do by other disciplines, especially in acute health care.

"Because people don't know what OT means."

“They'll be wondering: what you guys do exactly in this world? Help people get back to work or what?" [laughter]

However, students noted that as the workshop went on, they started to see others in their teams gaining an appreciation for what they had to offer toward the successful management of the case.

"But yes they were quite surprised like when we were focusing on leisure participation and social. We were taking it from a different perspective from them and were like "oh we never thought of it that way." So I think that was kind of surprising for some of them." - OT1 focus group 
"The dietitians-I thought that was a really good opportunity for them to actually put out on the table what they do and how important it is. I was surprised at how much they do". - SP focus group

However, some difficulties were noted with communication in their groups when using discipline specific terms.

\footnotetext{
"When one person comes up with an idea, [we'd need to] explain it, instead of just being like, "Oh you know, postural assessment," and then they go, "Oh, postural assessment," whereas like the dietitians would be like, "Why would you need that?"' OT2 focus group
}

\section{Effects on confidence}

Students felt their confidence had increased as a result of their participation in the workshop. They felt the knowledge that they had gained from their degree to date was validated by other disciplines not having this same knowledge. This appeared to help them better understand what their niche was, and feel that they could contribute to patient care by providing their unique set of skills. Many students noted that participating in the workshop greatly improved their confidence to undertake their upcoming clinical placement.

"This was good at this stage of study because we're going to be doing block prac[ticum] and we're going to be working with those professions. It gives us a chance to almost try that before we go out there." - OT1 focus group 
"Having that experience, of knowing what they would have done in that case. And then when you go out on placement, and maybe in a similar situation, you already have that background knowledge. - DT focus group

"My opinion was validated...basically my knowledge. You learn a lot in training and on paper... if you can apply that to an actual scenario... It's really good to know that what you're learning can be put into practice." - OT1 focus group

For some students, the confidence they gained from the experience helped to reassure them they would enjoy their future careers. Others felt more confident with practicing communication with health professionals outside their own discipline.

"It consolidated my learning and made me realise that I have chosen the right career path. For me that was really good." - OT1 focus group

"I think that this simulation helped to get us to put that hat on, when we sit around with other disciplines, we get a sense of, "This could be us in a year", talking with a dietitian, speech pathologist and it was really good to get that hat put on and all to be in control ... use our confidence." - OT2 focus group

\section{Working in a interprofessional environment}

For most students, this was their first experience doing an activity in an interprofessional team.

"It was a bit of a shock to some of the students who were actually participating on the day. They were like "Oh, we actually have to listen to your ideas too?" And "Oh, you're 
looking at this area, whereas we're looking at this area". So we had to kind of like come together and be like "Okay guys, we need to work as a team". - OT2 focus group

Some students were surprised by how similar the thought processes were between the different disciplines.

"We actually had a lot of similar thinking in how we approached the case, even from all the different disciplines." - OT1 focus group

Students appeared to enjoy the experience of working in a team with others from different backgrounds to their own.

"It's good to collaborate and combine to work out priorities and do that together." OT1 focus group

"We were working together and were then like "Oh yes, you know that is a really good point, we wouldn't have thought of that." - OT1 focus group

Students recognised that working together produced a much better outcome for the patient.

"I could say where the dietitian and the speech have worked together, but really never considered an OT before. So I thought maybe it's just how do you use utensils and stuff. I didn't actually consider that the sitting position would be so important." - DT focus group 
"The dietitian, OT and the speechie working together.... I think it was good to sort of see what they all brought to it. And by the end of the discussion we were all sort of thinking ... about what the other disciplines might be contributing." - SP focus group

The importance of advocating for your own profession when working was also noted.

"(We can) advocate for our own industry but also advocate for more to win together. I think this is why it was really good, because we need to learn that now, and not wait until we get out (into) the workplace, when it's too late." -SP focus group

\section{$\underline{\text { Suggestions for improvement }}$}

The uneven distribution of students was noted in all focus groups, with higher numbers of OT students in the working groups and only one dietetic student per group. Some suggested that only having one dietitian in a group meant the conversions were steered more towards the other two disciplines, in particular OT. Students thought a more even distribution of disciplines would lead to more variety in discussions.

"I kind of just sat in the background. I felt like I in some ways that I wanted to say [something] but I didn't feel like I could... Because I had some really strong, I suppose, personalities in the group that kind-of took over." -DT focus group

It was noted in two of the focus groups that inclusion of nursing students would improve the IPE experience. 
"It would be kind of cooler to get nursing involved as well, see where they are coming from." - DT focus group.

\section{DISCUSSION}

This study sought to pilot an innovative simulation-based IPE activity amongst OT, SP and DT students at a single academic institution in Western Australia. We were able to successfully implement the pilot program across three courses (two undergraduate and one postgraduate) working with course coordinators from the respective disciplines. We also sought to evaluate the simulation-based workshop from the student perspective, with a specific interest on whether the activity led to improved attitudes toward IPP.

Previous studies have documented the barriers towards implementing IPE activities in curricula, citing issues such as lack of student engagement and limited understanding of the role of other and their own disciplines (Kenaszchuk, Rykhoff, Collins, McPhail \& van Soeren, 2012; Titzer, Swenty \& Hoehn, 2012), lack of reliable information technology (Seefeldt et al., 2012), difficulties with provision of information in a succinct timeframe (Cameron et al., 2009), and poor participation rates (Bucklet et al., 2012; Davies et al., 2011). We were able to successfully facilitate a three-hour simulation-based IPE workshop that student feedback suggested was of an appropriate length, and covered an appropriate breadth of material. By ensuring participation in the workshop was mandatory by aligning participation with a pass mark in a respective unit in each course, we were able to address the issue of poor participation and uptake. While we acknowledge that baseline attitudes towards IPP were relatively high $(83 \%)$, we clearly noted a statistically significant improvement in attitudes towards IPP across all three disciplines, as measured by the RIPLS scale pre- and post-workshop. It is difficult to map whether this difference translates to clinical significance. However, with Cohen (1998) 
suggesting effect sizes $>0.80$ represent a large effect size, the corresponding effect size from this analysis $(d=0.90)$ does provide some indication. It was also interesting to note that there were no statistically significant differences in improvement of attitudes between our three study disciplines, even though DT students provided lower satisfaction scores than OT and SP students on our SDS scale. This may indicate that, although the DT participants were less satisfied with the experience-possibly due to the disparity of numbers from each discipline and feeling they were unable to contribute as much to discussion-the DT students still received comparable improvements in readiness for IPP.

Students across all three disciplines did suggest they were highly satisfied with the workshop. Focus group discussions suggested the case study presented was interesting and relevant for all disciplines. This was of particular interest to the project team, given the task of mapping a case ensuring relevance across three distinct disciplines, but also course progression of the students across each of the disciplines. There was a suggestion that it would be unlikely staff from each profession would in reality have the time to meet and discuss patients in actual clinical settings, such as was depicted in our video resources. Certainly, lack of time, resources and scheduling conflicts have been cited as barriers to effective IPP (Shrader et al., 2016; Wilkes \& Kennedy, 2017), and it was disappointing that even at the pre-licensure level students were aware of these limitations. This perhaps reinforces the importance of IPE at the pre-licensure level so that improved attitudes toward IPP can be translated through to the clinical setting.

Our SDS importance scale suggested having relevant learning objectives, access to feedback, and appropriate levels of fidelity (realism) were the most important factors that contributed toward student learning and satisfaction, which aligns with previous IPE research utilising SBL (Reece, Jeffries \& Engum, 2010). The structure and format of the workshop, as well as the 
simulation-based video resources resonated with the students, whereby they suggested it was highly beneficial to see an interprofessional team working together in a practical capacity, before being asked to do so themselves. Simulation-based video resources in IPE have been utilised in the past with varying levels of success. One study found nursing and medical students felt a series of simulation-based IPE video resources lacked realism and relevance (Kyrkjebø, Brattebø \& Smith-Strøm, 2006). These limitations were not found in this study.

Both the quantitative and qualitative data triangulated to suggest students felt they had an enhanced understanding of other discipline roles following completion of the workshop. Students reported they knew far more about the other disciplines as a result of completing the workshop. They also commented on how these enhancements in knowledge worked to engender a sense of ownership over their own learning and role, that understanding where their role overlapped and differed to other disciplines allowed them to better understand their role in relation to these other disciplines. This was associated with self-reported improvements in confidence amongst students. While changes in self-efficacy were not measured quantitatively, students consistently reported that improvements were noted as a result of the workshop in the focus groups. They suggested that this was of particular use with respect to their upcoming clinical practicums, for which some students were already harbouring some anxiety. They suggested that participating in the IPE workshop lessened this anxiety, enhanced confidence with their own skillset, and helped map their skillset against other disciplines. Student feelings of anxiety in association with clinical placements is well-documented (Chan, 2002; ChesserSmyth, 2005; Melincavage, 2011). Previous research makes clear that access to SBL environments works to improve learning whilst on clinical placement (Mills, Carter, Rudd, Ross \& Claxton, 2015). Future research could work to further understand the link between 
improved confidence resulting from IPE experiences prior to attending clinical placement, and diminished anxiety associated with clinical placement.

It is acknowledged that our research design is not without limitations. This study sought to address the feasibility of providing a simulation-based IPE workshop to OT, SP and DT students, measuring improvements in attitudes towards IPP, as well as evaluating the workshop as an avenue for IPE. Although follow up of long-term outcomes associated with IPE activities would be ideal, funding constraints often limit the ability of researchers to do this (Thistlethwaite, 2007), as was the case with our project. The majority of studies evaluating IPE activities typically fall into the first level of Kirkpatrick's (1994) model of training evaluation (i.e. reactions to the training program), and there are calls for researchers to undertake longitudinal work to provide evidence of the transferability of skills developed during IPE activities (Gough et al., 2012). However, our present study does distinguish itself from previous research by providing data on a novel collaboration of three under-represented cohorts in IPE research, being OT, SP and DT. The majority of IPE initiative evaluations focus on medical and nursing students (Hammick, Freeth, Koppel, Reeves \& Barr, 2007; Reeves et al., 2016), and the interprofessional interactions of allied health professions such as OT, SP and DT remains an under-researched area. This is likely due to these professions being younger and less established than medicine and nursing, but there are calls that attention, research and funding need to be expanded across other areas of allied health, given the ageing population sees allied health professionals (not including medical physicians and nurses) now making up more than $60 \%$ of the healthcare workforce (Demo, Fry, Devine \& Butler, 2015).

The knowledge that IPE initiatives utilising simulation resources can engender strong improvements in self-efficacy, improve attitudes towards IPP, and leave students highly 
satisfied with the teaching and learning experience, should be of particular relevance and interest to educators from these respective disciplines.

Our students gave valuable feedback for future IPE learning experiences. Students reported perceived value in extending involvement to other disciplines, most notably nursing. Those seeking to utilise the case presented in this research, using our delivery format, should consider the value of including nursing in the IPL experience. Further, students suggested that such an experience would have been equally, if not more, beneficial being provided earlier in their degree. Whilst students appreciated the timing of the workshop in relation to them poised to attend clinical practicums, they also felt that similar experiences, potentially with simpler case studies, would likely have been of great benefit earlier in their respective curriculums. Timing of provision of IPE experiences is something all educators will need to consider, taking into account the difficulties associated with providing a well-facilitated IPE experience across multiple courses. Multiple studies report the importance of considering the timing of IPE experiences to ensure optimal learning (Brewer, Flavell \& Jordon, 2017) Thistlethwaite, Kumar, Moran, Saunders \& Carr, 2015).

\section{Conclusion}

There is widespread support for implementing IPE in the health sciences, yet widespread implementation is not yet a reality (Buring et al., 2009). This study undertook a pilot evaluation of an IPE initiative that was incorporated into curricula across OT, SP and DT degrees. While it was outside the scope of the study to track long-term translation of learning as a result of the pilot programme, student feedback was clear in that the initiative engendered enhanced understanding of the role of other disciplines, and how their own discipline fit into interactions with these other disciplines, enhanced confidence with their own level of knowledge, which 
positively impacted on anxiety surrounding their upcoming clinical placement. Feedback also suggested a positive impact on attitudes towards working interprofessionally, and that students were highly satisfied with the learning they received as part of the initiative. This research demonstrated that a simulation-based, three-hour IPE workshop can have an immediate benefit on confidence and attitudes towards IPP for OT, SP and DT students. Educators of these (and other) allied health disciplines should consider the merits of incorporating simulation-based IPE activities into curricula to better prepare their health students for IPP in clinical settings.

\section{ACKNOWLEDGEMENTS}

The authors would like to acknowledge the clinicians who contributed to validation of the case study, with special mention to Associate Professor Deborah Hersh, Associate Professor Erin Godecke and Associate Professor Natalie Ciccone.

\section{DECLARATIONS OF INTEREST}

The authors have no declarations of interest to report.

\section{FUNDING}

This research was unfunded.

\section{REFERENCES}

Baker L, Egan-Lee E, Martimianakis M \& Reeves S. (2011). Relationships of power: implications for interprofessional education. Journal of Interprofessional Care, 25(2), 98-104.

Brewer M, Flavell H, Jordon, J. (2017). Interprofessional team-based placements: The importance of space, place, and facilitation. Journal of Interprofessional Care, 31(4), 429-437. 
Buckley S, Hensman M, Thomas S, Dudley R, Nevin G \& Coleman J. (2012). Developing interprofessional simulation in the undergraduate setting: experience with five different professional groups. Journal of Interprofessional Care, 26(5), 362-369.

Buring S, Bhusan A, Brazeau, G, Conway, S, Hansen, L \& Westberg. (2009). Keys to Successful Implementation of Interprofessional Education: Learning Location, Faculty Development, and Curricular Themes. American Journal of Pharmaceutical Education, 73(4), 60.

Cameron A, Rennie S, DiProspero L, Langlois S, Wagner S, Potvin M, ... Reeves S. (2009). An introduction to teamwork: findings from an evaluation of an interprofessional education experience for 1,000 first-year health science students. Journal of Allied Health, 38(4), 220226.

Cant R \& Cooper S. (2010). Simulation-based learning in nurse education: a systematic review. Journal of Advanced Nursing, 66(1), 3-15.

Centre for the Advancement of Interprofessional Education (CAIPE). (2013) Introducing Interprofessional Education - London: CAIPE. Retrieved from https://www.caipe.org/resources.

Chan D. (2002) Associations between student learning outcomes from their clinical placement and their perceptions of the social climate of the clinical learning environment. International Journal of Nursing Studies, 39(5), 517-524. 
Chesser-Smyth P. (2005) The lived experiences of general student nurses on their first clinical placement: A phenomenological study. Nurse Education in Practice, 5(6), 320-327.

Cohen J. (1988). Statistical Power Analysis for the Behavioural Sciences. (2nd ed.). Hillsdale, NJ: L. Erlbaum Associates.

Cox M, Cuff P, Brandt B, Reeves S \& Zierler B. (2016). Measuring the impact of interprofessional education on collaborative practice and patient outcomes. Journal of Interprofessional Care, 30(1), 1-3.

Davidson M, Smith R, Dodd K, Smith J \& O'Loughlan M. (2008) Interprofessional prequalification clinical education: a systematic review. Australian Health Review, 32(1), 111120.

Davies K, Harrison K, Clouder D, Gilchrist M, McFarland L \& Earland J. (2011) Making the transition from physiotherapy student to interprofessional team member. Physiotherapy, 97(2), $139-44$.

Demo D, Fry D, Devine N \& Butler A. (2015) A Call for Action: Advocating for Increased Funding for the Allied Health Professions ASAHP Leadership Development Program. Journal of Allied Health, 44(1), 57-62.

Franklin, A, Burns P \& Lee C. (2014) Psychometric testing on the NLN Student Satisfaction and Self-Confidence in Learning, Simulation Design Scale, and Educational Practices 
Questionnaire using a sample of pre-licensure novice nurses. Nurse Education Today, 34(10), $1298-1304$.

Goldkuhl, G. (2012) Pragmatism vs. interpretisvism in qualitative information systems research. European Journal of Information Systems, 21(2), 135-146.

Goldman J, Zwarenstein, M, Bhattacharyya O \& Reeves S. (2009) Improving the clarity of the interprofessional field: implications for research and continuing interprofessional education. Journal of Continuing Education in Healthcare, 29(3): 151-156.

Gough S, Hellaby M, Jones N \& MacKinnon R. A review of undergraduate interprofessional simulation-based education (IPSE). Collegian. 19(3), 153-170.

Hammick M, Freeth D, Koppel S, Reeves, S \& Barr H. (2007) A best evidence systematic review of interprofessional education: BEME Guide no. 9. Medical Teacher, 29(8), 735-751.

Hayashi T, Shinozaki H, Makino T, Ogawara H, Asakawa Y, Iwasaki K. ... Watanabe H. (2012) Changes in attitudes toward interprofessional health care teams and education in the first- and third-year undergraduate students. Journal of Interprofessional Care, 26(2), 100107.

Jeffries P \& Rizzoli M. (2006). Designing and Implementing Models for the Innovative Use of Using Simulation to Teach Nursing Care of Ill Adults and Children: A National, Multi-site, Multi-method Study. National League for Nursing, New York (NY). 
Kenaszchuk C, Rykhoff M, Collins L, McPhail S \& van Soeren M. (2012). Positive and null effects of interprofessional education on attitudes toward interprofessional learning and collaboration. Advances in Health Science Education, 17(5), 651-669.

Kirkpatrick D. (1994) Evaluating training programs: the four levels. Berrett-Koehler, San Francisco.

Kyrkjebø J, Bratteb $\emptyset$ G \& Smith-Strøm H. (2006). Improving patient safety by using interprofessional simulation training in health professional education. Journal of Interprofessional Care, 20(5), 507-516.

MacKinnon R. (2011). Editorial; the rise of the collaborative inter-professional simulation education network. Infant, 7, 6-8.

Melincavage S. (2011). Student nurses' experiences of anxiety in the clinical setting. Nurse Education Today, 31(8), 785-789.

Mills B, Carter O, Rudd C, Ross N. \& Claxton L. (2015). Clinical placement before or after simulated learning environments? A naturalistic study of clinical skills acquisition amongst early-stage paramedicine students. Simulation in Healthcare, 10(5), 263-269.

Olsen R \& Bialocerkowski A. (2014). Interprofessional education in allied health: a systematic review. Medical Education, 48(3), 236-246. 
Parsell G \& Bligh J. (1999). The development of a questionnaire to assess the readiness of health care students for interprofessional learning (RIPLS). Medical Education, 33(2), 95-100.

Reece C, Jeffries P \& Engum S. (2010). Learning together: Using Simulations to Develop Nursing and Medical Student Collaboration. Nursing Education Perspectives, 31(1), 33-37.

Reeves S, Fletcher S, Barr H, Birch I, Boet S, Davies N, ... Kitto S. (2016). A BEME systematic review of the effects of interprofessional education: BEME Guide No. 39. Medical Teacher, 38(7), 656-668.

Robertson J \& Bandali K. (2008). Bridging the gap: Enhancing interprofessional education using simulation. Journal of Interprofessional Care, 22(5), 499-508.

Seefeldt T, Mort J, Brockevelt B, Giger J, Jordre B, Lawler M, ... Svien L. (2012). A pilot study of interprofessional case discussions for health professions students using the virtual world Second Life. Currents in Pharmacy Teaching and Learning, 4(4), 224-231.

Shrader S, Hodgkins R, Laverentz D, Zaudke J, Waxman M, Johnston K \& Jernigan S. (2016). Interprofessional Education and Practice Guide No. 7: Development, implementation, and evaluation of a large-scale required interprofessional education foundational programme. Journal of Interprofessional Care. 30(5), 615-619.

Thistlethwaite J. (2007). Interprofessional education in Australia. Journal of Interprofessional Care, 21(4), 369-372. 
Thistlethwaite J. (2012) Interprofessional education: a review of context, learning and the research agenda. Medical Education, 46, 58-70.

Thistlethwaite J, Kumar K, Moran M, Saunders R \& Carr S. (2015). An exploratory review of pre-qualification interprofessional education evaluations. Journal of Interprofessional Care, 29(4), 292-297.

Titzer J, Swenty C \& Hoehn W. (2012) An interprofessional simulation promoting collaboration and problem solving among nursing and allied health professional students. Clinical Simulation in Nursing, 8(8), 325-333.

Watt-Watson J, Hunter J, Pennefather P, Librach L, Raman-Wilms L, Schreiber M, ... Salter M. (2004). An integrated undergraduate pain curriculum, based on IASP curricula, for six health science faculties. Pain, 110(1-2), 140-148.

Wilkes M \& Kennedy R. (2017). Interprofessional Health Sciences Education: It's Time to Overcome Barriers and Excuses. Journal of General Internal Medicine. 32(8), 858-859.

Williams B, Brown T \& Boyle M. (2012) Construct validation of the readiness for interprofessional learning scale: A Rasch and factor analysis. Journal of Interprofessional Care, 26(4), 326-332. 